\title{
Hidden in Plain Sight: \\ The Bystander Effect and the Mobilisation of Modern Slavery Whistleblowing

\author{
Mark Stevenson
}

\author{
Department of Management Science, Lancaster University Management School
}

Lancaster University, LA1 4YX UK

\section{Abstract}

Purpose: To provide new insight into the modern slavery threat, and to enhance its detection in supply chains by understanding and addressing barriers to whistleblowing. A broad definition of a whistle-blower is adopted, which includes any witness internal or external to an organisation.

Design/methodology/approach: A viewpoint paper that includes using news reports and other secondary data sources on a recent modern slavery scandal in garment factories in Leicester, UK and the lens of the bystander effect from the social psychology literature. The core focus is on whistleblowing by members of the local community in which an operation or supply chain is embedded.

Findings: The phenomenon of modern slavery being an "open secret" within the local community is highlighted. But rather than the case being characterised by widespread whistleblowing, the problem only came into full focus when poor working conditions and forced labour during COVID-19 lockdown restrictions contributed to the spread of the virus. It is argued that overcoming this "bystander effect" can lead to the greater mobilisation of modern slavery whistleblowing.

Originality: The first paper to focus on operationalising the practice of whistleblowing as a source of greater supply chain intelligence to aid modern slavery detection. Causes of the bystander effect include the perceived low-emergency threat of modern slavery, the high-ambiguity environment, a low bystander responsibility, and low assistance/intervention incentive. Countermeasures include elevating the emergency status of modern slavery, creating a shared sense of responsibility for tackling the problem, having clear reporting channels, and taking swift and consistent action when instances of modern slavery are detected.

Research limitations/implications: Two sets of propositions and a conceptual model are provided; and seven future research suggestions are outlined, including extending the present study to whistle-blowing by victims and other internal members of an organisation or supply chain.

Practical implications: If it can be mobilised, whistleblowing has the potential to be an important part of detecting modern slavery, either temporarily replacing audits where they are not possible due to social distancing restrictions or directing the use of limited auditing resources to high-risk factories. In this way, combinations of practices can be effectively employed to tackle the threat.

Social implications: Contributes to addressing an important societal problem and one of the grandest challenges facing modern-day supply chains. This, it has been argued, is an even bigger problem now than ever before given the economic and market conditions created by the COVID-19 global pandemic.

Keywords: Modern slavery; social sustainability; supply chain; bystander effect; whistleblowing. Paper Type: Viewpoint paper 


\section{Introduction}

Modern slavery is a major social problem that, it is argued here, can best be tackled collectively by the global community. This includes focal buying firms, suppliers, and other traditional supply chain actors; non-traditional supply chain actors, including third-party agencies; governments and members of the wider community all playing their part. It is argued here that supply chains are missing out on a potentially important source of intelligence about the modern slavery threat if community members are not mobilised to take action in the form of whistleblowing when they become aware of risk indicators. This continuous monitoring mechanism in the communities where a firm's supply chain is embedded could help to protect victims and the integrity of the goods and services delivered to consumers. Yet whistleblowing is under-utilised and has received only very limited attention in the operations and supply chain management literature.

A broad definition of whistleblowing is adopted here to include any act of information disclosure that seeks to draw attention to wrongdoing by or within an organisation. Disclosure is typically motivated by it being in the interests of the workers or general public, with a view to bringing about a positive change in practices. Unlike in Jubb (1999), Andrade (2015) and many other sources, the scope of whistleblowing is not limited to actors internal to the organisation itself. Rather, it is argued that whistleblowing may be undertaken by anyone in a position to witness or suspect an organisation of wrongdoing. In the case of modern slavery, given the particular characteristics of the threat, whistleblowing by workers, including the victims themselves, is extremely challenging. Thus, whistleblowers can be actors internal to the organisation under suspicion, e.g. the victims or other employees; actors internal to the supply chain, e.g. suppliers, customers, logistics providers, etc. that interact directly with the organisation; actors internal to the wider industrial environment; or actors external to the supply chain or industry sector, e.g. the general public and local community. Witnesses may report their concerns to the company itself, to other high-profile firms in the supply chain, or to external parties, such as industry regulators, the media, trade unions or legal authorities. In some cases, this activity is supported by anonymous mobile phone applications, websites and hotlines.

This paper was triggered by a recent high-profile scandal in the UK of modern slavery being allegedly detected in the supply chain of a popular (predominantly) online fashion retailer. After the scandal was widely documented in the British media, it became clear that this was a known problem in the local community but one that had gone largely unreported - an open secret, hidden in plain sight. Thus, the main focus of this article is on whistleblowing by the general public. This can be complemented in the future such as by a focus on whistleblowing by workers and victims themselves, where possible. By overcoming this so-called "bystander effect", as studied in the social psychology literature, focal firms can enable actors in their supply chains and communities to whistle-blow thereby enhancing their sources of supply chain intelligence.

The central view expressed in this article is that whistleblowing can be a valuable weapon in the fight against modern slavery, especially when combined with targeted auditing. But this is only possible 
if witnesses report their evidence and if the recipients of the reports take it seriously by responding accordingly. The paper uses insights from the bystander behaviour literature to put forward an argument for why greater whistleblowing behaviour does not take place and outlines how this can be encouraged in the future. It begins with a brief overview of the literature on modern slavery, highlighting its focus on individual practices, its limited coverage of whistleblowing, its primary focus on traditional supply chain actors and its lack of connectivity with the wider community in which firms and supply chains are embedded. The paper then uses newspaper reports and other secondary sources to unpack the recent UK scandal, providing a rare in-depth account of one particular case of alleged modern slavery, before going deeper into the bystander effect and how this can be overcome, leading to two sets of propositions and a conceptual model. The paper then provides a brief discussion, including seven avenues for future research, before concluding.

\section{Modern Slavery in Supply Chains}

A recent spurt of research attention on modern slavery in the operations and supply chain management literature has appeared as a particular stream of work on socially sustainable supply chain management. This builds on broader literature outside the field that has been concerned with forced labour for a longer period of time (e.g. Cooke, 2003; Barrientos \& Smith, 2007; Barrientos, 2008 and 2013; Crane, 2013; Kara, 2017). Two conceptual thought-pieces on modern slavery in supply chains first appeared by UKbased academics (Gold et al., 2015; New, 2015) following the introduction of the California Transparency in Supply Chains Act and as the UK prepared for the introduction of its own Modern Slavery Act, 2015. The two papers served to stimulate the supply chain management research community to contribute to addressing the problem of modern slavery. Subsequent work has largely concentrated on: (i) studying how firms are responding to the introduction of the legislation; (ii) evaluating the outcomes of the legislation on firm performance; and, (iii) identifying contingency factors that explain the heterogeneity of firm responses. Much of the focus has been on (i), but it is likely that the body of literature in (ii) and (iii) will grow as the field matures and as the depth of secondary data on firm responses and performance effects develops.

In the first strand, Benstead et al.'s (2018) action research highlighted the importance of horizontal collaboration between apparel firms for making sense of the threat and tackling modern slavery. The focus of the work is on the roles played by traditional supply chain actors and NGOs. It does not extend, for example, to connections with other stakeholders in the local community or government. Benstead et al. (2020) later highlighted the limitations of a standard social audit and described a specific action research project that employed a newly designed audit protocol targeted at identifying indicators of modern slavery in a South East Asian garment factory. Although it focused on one practice only, the work demonstrated the challenges of detecting this hidden, criminal activity, including the resourceintensive nature of a targeted modern slavery audit. The work demonstrated that such an audit could be effective but that it is difficult to scale up to the size and complexity of many global supply chains. 
Thus, whistleblowing could be a complementary, continuous source of supply chain intelligence that helps a firm determine where to direct its limited detection resources for periodic auditing. In addition, Stevenson \& Cole (2018) conducted a qualitative analysis of modern slavery statements produced by fashion and textile firms in response to the 2015 UK modern slavery act, highlighting how firms are detecting and remediating the threat. Methods of detection included making workers, supply chain actors and the general-public aware of the signs of modern slavery and encouraging them to whistleblow, either to the buyer or directly to the authorities. A range of practices were identified, but the interconnections between the practices were not explored.

In the second strand, Birkey et al. (2018) found a significant negative market reaction to the passing of the California Transparency in Supply Chains Act, especially for larger firms and companies facing greater supply chain risks. Later, Cousins et al. (2020) studied the shareholder wealth effects of the UK modern slavery act; but their event study found no significant evidence of an effect on stock price. The authors did however find that firms with a history of addressing slavery issues can leverage a competitive advantage, thereby highlighting the economic benefits of implementing socially responsible sourcing practices. Finally, in the third strand, Flynn (2019) developed a predictive model to examine the organisational and environmental factors that determine corporate compliance with modern slavery reporting using data from Financial Times Stock Exchange 350 firms. Compliance was found to be significantly related to firm size, network involvement, prior social responsibility commitment, headquarter base, and industry sector (see also Flynn \& Walker, 2020).

In addition to the above, Trautrims et al. (2020) have recently published a new thought-piece and call to arms, arguing that the COVID-19 pandemic exacerbates the threat of modern slavery and increases the vulnerability of workers. Contributing factors include the state of the economy, sudden shifts in demand patterns and supply disruptions coupled with challenges to implementing mitigation practices due to social distancing measures and a relaxation of some labour regulations to enable vital Personal Protective equipment (PPE) to be produced more flexibly.

From the above it follows that modern slavery is a major, prevailing problem in supply chains that, without a significant shift in approach, looks set to become only more widespread in the post-COVID19 era. Its particular characteristics and challenges mean that although modern slavery can be seen as an acute type of social sustainability risk, it deserves dedicated attention and its own specific practices for detection and remediation. Yet, research in the field of operations and supply chain management on the topic is at a relatively nascent stage of development and has not connected supply chains to the local communities in which they are embedded. Although a range of separate practices for detecting modern slavery have been outlined in the literature, and it has been demonstrated that augmenting standard social audits to assess a worker's background and employment status or to detect low wages and the presence of exploitative third-party labour agents, can be effective, such practices are difficult to scale up to the size and complexity of many global supply chains. Thus, other practices, including whistleblowing, become an important source of supply chain intelligence that could help to direct the 
use of scarce firm resources for detection via targeted audits. This, however, is undermined if observers within the supply chain or wider community do not feel empowered or motivated to act upon indicators of modern slavery. The case described in the following section seeks to provide new insight into modern slavery whilst highlighting the phenomenon of a bystander effect that inhibits whistleblowing. The paper subsequently seeks to enhance modern slavery detection by understanding and addressing causes of the bystander effect.

\section{Triggering Case: Modern Slavery in UK Garment Factories}

In June 2020, as national lockdown measures around England imposed to stem the spread of COVID19 were being gradually relaxed, the East Midlands city of Leicester was being plunged into a strict, localised lockdown. This included the closure of non-essential retail outlets from the $30^{\text {th }} \mathrm{June}$ and the closure of schools from $2^{\text {nd }}$ July. This was a risk mitigation response to a spike in infections in the area, reflected in the COVID-19 reproduction rate. As this was the first UK city to face local lockdown restrictions, it received significant media attention that sought to uncover the causes of the spread. Attention quickly fell on Leicester's garment factories and their cramped working conditions. In particular, it was claimed that many of the recent COVID-19 cases were of workers from some of the many garment factories in the city.

It was alleged that some factories, housed in cramped, poorly ventilated buildings that facilitated transmission of the virus (The Guardian 2020a) had continued to operate during the national lockdown, flouting government rules, and prompting a National Crime Agency investigation. It was also claimed that workers were being paid as little as $£ 3.50$ per hour, well below the minimum wage, and experiencing poor working conditions in which social distancing measures were absent and PPE not worn (BBC, 2020a; The Guardian, 2020b). These claims were supported by an undercover reporter working for The Times who infiltrated one of the factories and spent two days packing boxes with garments destined for high street and online retailers (The Times, 2020a). Some workers who spoke to reporters anonymously claimed they faced intimidation when they asked for sick leave and were told to ignore self-isolation protocols despite having symptoms of the virus (The Guardian, 2020a). Many of the factory workers were from ethnic minority backgrounds, often born outside the UK and with limited language abilities and employment prospects, meaning they were often either unaware or misinformed of their rights making them vulnerable to exploitation. Further, poor wages combined with the UK's cost of living means workers can end up in debt bondage to their employers and gang masters, leaving them trapped and dependent on their employers. Meanwhile, some workers were illegally residing in the country or had a fragile migration status meaning they feared speaking out about their experiences.

It was claimed that one particular factory at the heart of the scandal was supplying boohoo.com and its subsidiaries through a subcontract arrangement (e.g. The Times, 2020b). Boohoo.com has since distanced itself from the factory (The Independent, 2020a) before a number of other high street retailers 
similarly dropped the factory from their supply chains. It was claimed that Boohoo.com themselves were also subsequently dropped by firms like Next, ASOS and Zalando (BBC, 2020b). The firm's brand value experienced a significant shock in the aftermath of the scandal, and they vowed to invest millions of pounds in investigating malpractice in their supply chain (The Guardian, 2020c). This shock occurred after the firm's sales had been up 45\% in the three months before May 2020 (The Guardian, 2020a) fuelled by a surge in demand for loungewear clothing during the national lockdown and the inability of high-street-only retailers to respond to online-only demand (The Guardian, 2020d; The Washington Post, 2020). In fact, it has been claimed that some of the unscrupulous factories in Leicester supplying the fast fashion industry doubled their capacity during lockdown to cope with demand (BBC, 2020c).

On the $8^{\text {th }}$ July 2020, boohoo.com appointed a member of the Queen's Counsel, Alison Levitt QC, to undertake an independent review into the firm's Leicester supply chain operations. Her report, which was published on the $24^{\text {th }}$ September $2020^{1}$, made a series of recommendations. These included promoting as many Tier 2 companies to Tier 1 as possible to establish a direct contractual relationship; regularly publishing a list of Tier 1 and Tier 2 suppliers; establishing a new committee focusing entirely on supply chain issues; setting targets for educating buyers around the topic of modern slavery and the actual cost of fabricating garments; expanding the company's KPIs beyond a commercial interest in growth and profitability to include ethical and sustainability issues, with knock-on implications for the structuring of bonus payments for buyers; and committing to placing a mixed set of orders with suppliers that includes high-margin items that cross-subsidise low-margin items. Later, in November 2020, and further making good on its pledge to invest millions in investigating supply chain malpractice, the company appointed a former high court judge to build on Levitt's enquiry, review its business practices and bring about change (BBC, 2020d; The Independent, 2020b).

A chronology of events surrounding the above scandal and the local context in Leicester is provided in Table 1. Meanwhile, a detailed chronology predating 2020 is available in Levitt's report outlining the history of allegations against Leicester factories.

https://www.boohooplc.com/sites/boohoo-corp/files/final-report-open-version-24.9.2020.pdf (last accessed 27th October 2020). 


\begin{tabular}{|c|c|}
\hline Date & Events \\
\hline $20^{\text {th }}$ April 2020 & $\begin{array}{l}\text { UK government permits companies to delay the publication of their modern slavery statement by up to } 6 \text { months due to the effects of } \\
\text { COVID-19, but firms that delay the publication must state the reason for any delay. }\end{array}$ \\
\hline $19^{\text {th }}$ May 2020 & Boohoo.com publishes a Supply Chain Code of Conduct and Supplier Guidance Tool, developed with an NGO. \\
\hline $2^{\text {nd }}$ June 2020 & Boohoo.com suppliers are invited to sign its Code of Conduct and disclose all sub-contractor arrangements. \\
\hline $28^{\text {th }}$ June 2020 & The Home Secretary confirms that the UK government is considering imposing a local lockdown on Leicester. \\
\hline $29^{\text {th }}$ June 2020 & $\begin{array}{l}\text { The Health Secretary announces the reintroduction of stricter lockdown measures for Leicester, including the closure of non-essential } \\
\text { retailers and schools. }\end{array}$ \\
\hline $30^{\text {th }}$ June 2020 & Non-essential retailers in Leicester close. \\
\hline $2^{\text {nd }}$ July 2020 & The (re-)closure of schools in Leicester begins. \\
\hline $3^{\text {rd }}$ July 2020 & New regulations are pushed through parliament to give the police the powers to enforce lockdown restrictions in Leicester from $4^{\text {th }}$ July. \\
\hline $4^{\text {th }}$ July 2020 & New powers/restrictions come into force. \\
\hline $5^{\text {th }}$ July 2020 & $\begin{array}{l}\text { The rise in COVID-19 cases is linked to conditions in garment factories in Leicester. A Sunday Times investigation links boohoo.com } \\
\text { indirectly to modern slavery in Leicester. }\end{array}$ \\
\hline $6^{\text {th }}$ July 2020 & The Guardian reports that more than $£ 1$ bn has been removed from boohoo.com’s valuation. \\
\hline $7^{\text {th }}$ July 2020 & The BBC reports that boohoo.com has been dropped by other well-known retailers. \\
\hline $8^{\text {th }}$ July 2020 & Alison Levitt QC is appointed to conduct an independent review into boohoo.com's Leicester supply chain operations \\
\hline $11^{\text {th }}$ July 2020 & $\begin{array}{l}\text { Belgium includes Leicester on its "red zone" list, meaning anyone who has recently visited the city must quarantine for } 14 \text { days on arrival in } \\
\text { Belgium. }\end{array}$ \\
\hline $13^{\text {th }}$ July 2020 & It is reported that as many as 10,000 workers in Leicester factories could be experiencing modern slavery conditions. \\
\hline $16^{\text {th }}$ July 2020 & $\begin{array}{l}\text { The Health Secretary announces that the Leicester local lockdown is to be extended, albeit with a redrawing of the city boundaries affected } \\
\text { by the lockdown. }\end{array}$ \\
\hline $3^{\text {rd }}$ August 2020 & Restaurants, pubs and hairdressers in Leicester are allowed to reopen as lockdown restrictions are loosened in the city. \\
\hline $5^{\text {th }}$ August 2020 & $\begin{array}{l}\text { Levitt's independent review calls for the public to come forward with information in relation to the working conditions in factories in } \\
\text { Leicester supplying boohoo.com, resulting in } 39 \text { responses from individuals and organisations. This includes an online evidence submission } \\
\text { questionnaire available in seven languages. }\end{array}$ \\
\hline $12^{\text {th }}$ August 2020 & $\begin{array}{l}\text { A team of forensic accountants instructed to support the independent review, e.g. to check the material provided by boohoo.com, evaluate } \\
\text { whether information was being concealed, and judge the board's standards of governance. }\end{array}$ \\
\hline $10^{\text {th }}$ September 2020 & Alison Levitt QC and her team visit a selection of Leicester factories together with an independent, ethical audit company. \\
\hline $24^{\text {th }}$ September 2020 & $\begin{array}{l}\text { A 234-page independent review into the boohoo.com Group PLC's Leicester supply chain is published, finding that the company did not } \\
\text { break any laws but also confirming low rates of pay and poor working conditions in factories in Leicester supplying boohoo.com, which it is } \\
\text { claimed were known to senior members of the board by December } 2019 \text { at the latest but which were not attended to with sufficient urgency. }\end{array}$ \\
\hline $26^{\text {th }}$ November 2020 & Former high court judge, Sir Brian Leveson, appointed to institute change at boohoo.com. \\
\hline
\end{tabular}

Table 1: Brief Summary of Key Events Connected to the Focal Case 
One particularly notable and unexpected phenomenon evident in the Leicester scandal was the admission that the city's 'sweatshops' had been an open secret, "hidden in plain sight" (The Telegraph, 2020). In other words, it was common knowledge in the local community that working conditions in some of the city's garment factories were poor and yet the issue went largely unaddressed. This is despite it being stated in boohoo.com's 2019 modern slavery statement ${ }^{2}$ that they have an external whistle-blowing policy that is available on the company's website ${ }^{3}$ allowing anyone within or outside the boundaries of the firm or supply chain to raise concerns about supplier activities. This policy includes raising concerns about health and safety, unacceptable working environments, dishonest work practices such as the use of unapproved subcontractors, or violation of the group's modern slavery policies or code of conduct. Once the scandal did break, The Times declared "the secret's finally out" and called for this to be a catalyst for closing sweatshops (The Times, 2020b). Thus, it is concluded that one of the tools available to organisations to gather intelligence on their supply chains and detect modern slavery - whistleblowing - is not proving to be effective in this context. It is argued here that whistleblowing in a broad sense can take many forms and involve various actors, including workers and members of the general public. The former however is problematic given the control and intimidation tactics employed by some gang masters and the vulnerability of the workers; whereas, enabling the latter would provide an important supplementary source of supply chain information.

Section 4 now focuses in detail on overcoming barriers to whistleblowing by the general public and local community using the bystander effect literature, leading to two sets of propositions and a conceptual model. This focus emerged from reading about the focal/triggering case in the popular press and identifying the bystander effect as an interesting phenomenon that had also been a characteristic in at least one other previous modern slavery tragedy. In 2004, 23 cockle-pickers died at Morecambe Bay (UK) after being stranded in rising tides (The Guardian, 2004). Local residents are said to have been aware that many of the cocklers were illegal immigrants from China who were being exploited (Lancs Live, 2019) yet the problem did not come to light until after tragedy struck. Further in-depth research into the bystander effect was then conducted and reflected upon in order to confirm its fit with the modern slavery context. Abstractions from the secondary case evidence and other experiences were combined with deductions from the literature to develop the propositions. In keeping with the viewpoint paper style, this is an opinion to be built upon more formally in future research.

https://www.boohooplc.com/sites/boohoo-corp/files/all-documents/Modern-slavery-statement-2019.pdf (last accessed 27th October 2020). https://www.boohooplc.com/sustainability/supply-chain-review/whistleblowing-policy (last accessed 27th October 2020). 


\section{Emerging Phenomena: The Bystander Effect}

The bystander effect (Darley \& Latané, 1968, 1970), as described in the social psychology literature (Levine, 2012), posits that people are less likely to help someone in need as the number of other people present and aware of the need for help increases, leading to a diffusion of responsibility. It is also known as the Genovese Syndrome as Darley \& Latané's $(1968,1970)$ laboratory studies were triggered by the assault and murder of a woman called Kitty Genovese in 1964 that was witnessed by many bystanders who failed to intervene in or report the tragic events as they unfolded. The bystander effect has received only limited attention in the business and management literature (e.g. Dozier \& Miceli, 1985; MesmerMagnus \& Viswesvaran, 2005; Gao et al., 2015). For example, Gao et al. (2015) examined the propensity of lower level employees to raise concerns about working practices according to whether or not the reporting channel is administered internally or externally. The study found that employees are more likely to blow the whistle when reporting externally, which may imply concerns for their own job security or the degree to which the report would be taken seriously internally. To the best of the author's knowledge, the bystander effect has not been considered in the modern slavery literature or specifically in a supply chain management context.

Darley \& Latané (1970) outlined key steps towards intervention, whereby a witness or observer recognises that something is happening; interprets the situation as an emergency; assesses their degree of responsibility; and evaluates alternative forms of direct or indirect intervention, before implementing a chosen course of action. A bystander fails to take action despite witnessing events, effectively decoupling cues from response actions, for a variety of reasons, including their perception of the emergency status of a situation, the degree of ambiguity in the environment, their sense of responsibility, and the incentive to assist/intervene. This lens, it is argued, has utility for furthering our understanding of modern slavery and how communities can be mobilised to help tackle the threat. By using the above broad principles of the bystander effect and applying them to the modern slavery context, two sets of propositions are put forward on: (1) the bystander effect, its causes and impact in the context of modern slavery; and, (2) how causes of the bystander effect can be overcome to provide greater supply chain intelligence on the modern slavery threat posed to supply chains. The central argument is summarised in the following overarching propositions (P1 and P2):

P1: The bystander effect decouples witnessing indicators of modern slavery risk from indirect interventions via whistleblowing.

P2: Overcoming causes of the bystander effect can provide organisations with a new and continuous stream of intelligence on their supply chains, which can be used to direct the use of limited auditing resources to the most high risk nodes to periodically detect and tackle the modern slavery threat.

Sections 4.1 to 4.4 unpack four key factors contributing to the bystander effect and how they can be tackled in order to develop midrange theory in the form of eight more specific propositions that 
elaborate on P1 and P2. In each subsection, one specific proposition is put forward that unpacks P1 (P1a-1d) and one specific proposition is put forward that unpacks P2 (P2a-2d). This is followed by Section 4.5, which provides an overall conceptual model (Figure 1). The propositions are indicated within the conceptual model.

\subsection{Emergency Situations}

After becoming aware of signals or indicators of a threat/problem, a witness's assessment of whether the situation is an emergency and how serious the consequences will be affects whether or not they intervene (Fischer et al., 2011). Thus, a person is more likely to intervene in a high-emergency situation than in a low-emergency situation (Mason \& Allen, 1976). In the context of modern slavery, a person's interpretation or assessment of the extent to which the situation is an emergency is highly subjective and partly informed by their prior understanding of modern slavery and its consequences. Rather than being a discrete, high-impact event like a car crash, modern slavery is a gradual and continuous problem, albeit one that may contribute to or exacerbate the consequences of a major critical event, such as a building collapse or factory fire. For example, modern slavery did not occur on one single day in the Leicester factories - it was a persistent menace. This means that there is not a single, major triggering event prompting someone to make a report, but it also means that there are likely to be many opportunities to make an intervention. Overall, many bystanders may interpret modern slavery as a lowemergency situation and this may be reinforced by the hidden nature of the problem causing observers to suspect something is wrong but without having any overwhelming, hard evidence. It therefore becomes important to address perceptions of the problem and its emergency status. This begins with heightening awareness amongst the public of the signals or indicators of modern slavery to look out for in addition to raising the profile of the threat posed by modern slavery, its consequences for the victims and its interconnectedness with human trafficking and other forms of organised crime. This discussion leads to the following:

P1a: Modern slavery is not a single, one-off emergency but rather a gradual, continuous threat. This, coupled with the hidden and complex nature of the problem, leads witnesses to conclude that modern slavery is a low-emergency scenario not requiring an urgent intervention.

P2a: Elevating perceptions of the emergency status of modern slavery - by building greater awareness of the problem, signs of its existence, its consequences and links to organised crime - will lead to more widespread whistleblowing interventions, thereby providing greater supply chain intelligence on the modern slavery threat.

\subsection{Ambiguity}

Another important factor affecting bystander behaviour is the degree of ambiguity surrounding the situation whereby the greater the degree of ambiguity, the longer it takes individuals to respond to a situation (Clark \& Word, 1972). Modern slavery could be seen as a highly confusing and ambiguous 
context. For example, it is not clear to witnesses what a victim is being paid, whether closing the factory is best for the workers if they have no other means of survival, whether a victim wants to be freed from their situation, particularly in the post-COVID economic environment and when there are no physical, observable chains involved in debt bondage. Hence, this factor could explain delays to modern slavery whistleblowing, especially in the Leicester case. The effects of ambiguity are also connected to the presence of other onlookers and how they interpret the situation and respond. For example, Latané \& Rodin (1969) found that in high-ambiguity contexts, observers look to other observers for guidance and that onlookers can misread each other's hesitation for a lack of concern for the victim or situation. Modern slavery might be seen as a broad societal problem meaning witnesses evaluate the problem as being well-known to others. As a result, they either assume others will have reported the problem or conclude that society has deemed this to be acceptable behaviour, and so they 'turn a blind eye'. Again, a key issue for overturning the bystander effect is creating greater understanding of the problem of modern slavery in society and of the plight of its victims. This discussion leads to the following:

P1b: The highly ambiguous nature of the modern slavery threat - linked to a lack of visibility around the degree of worker exploitation and the inaction of other witnesses - contributes to the decoupling effect between indicators of modern slavery and indirect interventions via whistleblowing.

P2b: Creating a greater sense of understanding within communities about the modern slavery threat and its impact on victims will lead to more widespread whistleblowing interventions, thereby providing greater supply chain intelligence on the modern slavery threat.

\subsection{Sense of Responsibility}

A person's feeling of responsibility is influenced, for example, by whether or not they believe someone is deserving of help and by the relationship between the bystander and the victim (Darley \& Latané, 1970). Related to this is the status of the victim in society (Solomon et al., 1982). This is a complex issue in the context of modern slavery, especially where a migrant, potentially illegal workforce is involved. This can change perceptions of the workers as victims while cultural distance makes it more difficult for the witness to relate to the victim, reducing their propensity to take action. In the Leicester case, it was reported that many factory workers were from ethnic minority backgrounds, often born outside the UK, with varying degrees of migration status (The Guardian, 2020a). Thus, the workers were marginalised in society while a number of other intersectional issues were also at play involving class, race, religion, gender, etc. This can lead to the observer lacking a sense of responsibility towards whistleblowing.

There is also a complex relationship with responsibility created by the observer potentially being a part of the problem in the sense that they themselves may be users of products or services created with the help of cheap, undervalued labour. This may lead to internal turmoil for the individual that either makes them more or less likely to take action. Consumer complicity has received only limited attention 
in the context of modern slavery (e.g. Carrington et al., 2020), while the same can be said, for example, of counterfeit products (e.g. Chaudhry \& Stumpf, 2011). The degree of responsibility is also diminished if witnesses perceive modern slavery to be a problem for large organisations to address, as might be implied by the UK's modern slavery legislation that puts the onus on firms with a turnover greater than $£ 36$ million to report each year on modern slavery in their supply chains. Thus, responsibility is deflected or elevated to other actors who themselves have sometimes failed to comply with the legislation, undermining signals that this is an important problem to address (e.g. Stevenson \& Cole, 2018; Voss et al., 2019).

Overcoming the many issues raised here is complex and will require cultural change within communities and consumer markets. Community projects, for example, could be initiated that start to address marginalisation and build cohesion, bringing culturally-distant groups closer together. Meanwhile, in the context of the garment industry, there needs to be a shift away from the throw-away culture of fast fashion towards a more durable, reusable slow fashion ethos. This may rely, for example, on raising consumer awareness of the need to accept longer lead times and higher prices. More generally, there needs to be a greater sense of shared responsibility amongst all actors. Large firms need to play their role in addressing modern slavery and avoid becoming embroiled in blame wars with other actors, and governments need to enforce their own legislation where necessary. Firms also need to look at their own sourcing decisions and practices, potentially embarking on greater vertical integration whilst simultaneously not assuming reshoring will automatically reduce risk. They could also seek to develop a collective sense of responsibility through greater horizontal collaboration, with firms sharing knowledge and pooling resources to combat the threat. Further, by working together and taking joint action, firms have greater power/leverage as the consequences of non-compliance for the supplier are greater (Benstead et al., 2018). Meanwhile, there are also roles to be played by other ecosystem members, including tier one suppliers, sub-tiers, NGOs, third-party auditing and training firms, etc. in changing attitudes and creating greater transparency. This discussion leads to the following:

P1c: A witness's sense of responsibility towards the victims of modern slavery is affected by the social and cultural distance between the witness and victim, and complicated by both complicit consumer behaviour and the strength of the signals sent by other actors that are in a greater position of authority or responsibility.

P2c: Increasing the individual and collective sense of responsibility amongst witnesses and communities will lead to more widespread whistleblowing, but this is reliant on addressing the underlying causes of marginalisation, building community cohesion, and developing a more sustainable culture. 


\subsection{Assistance/Intervention Incentives}

A final important factor considered here is the alternative forms of assistance available or the ease of taking action, including via direct intervention to assist the victim and via detour or indirect intervention, whereby a report is made to the relevant authorities (Latané \& Darley, 1968). In the case of modern slavery, the practice involves criminal activity, which means that a direct intervention could put an observer in danger. Such an intervention is also problematic given that modern slavery is not a discrete, single event that triggers an intervention. Thus, an indirect intervention is the more likely course of action. This however is challenging for a number of reasons, reducing the incentive to assist or intervene. First, it can be difficult to determine who to report the situation to, especially given the multiplicity of authorities and stakeholders involved. For example, in the UK, this might include the national crime agency, Her Majesty's revenue and customs, the department for work and pensions, the gang masters and labour abuse authority, immigration, the local council, a trade union, focal buyers/brands, etc. In the case of boohoo.com, Levitt's report notes that the company has now appointed a Head of Compliance who has, for example, made contact with authorities to determine a single point of contact for reporting allegations that originate from whistle-blowers or the company's own factory audits. This elevates concerns beyond the boundaries of the firm to an independent entity with the authority to investigate. Second, motivation to report is undermined when companies or authorities are accused of not taking the problem seriously or when they fear taking action. For example, companies have been accused of making token responses to modern slavery legislation only (Stevenson \& Cole, 2018) and, in the Leicester case, the government and firms were criticised for ignoring earlier warning signs and failing to take action (Financial Times, 2020; The Guardian, 2020e). At one point, it was claimed the police were hesitant in case they were accused of being racist (The Daily Mail, 2020b).

It therefore follows that it is important for the channels of reporting to be clear and readily available. Whistleblowing apps should provide an easily accessible means of reporting incidents anonymously, with a lack of anonymity also being a contributing factor to the bystander effect (Schwarz \& Gottlieb, 1980; You \& Lee, 2019). Finally, it is important that governments and large organisations send out the right signals about modern slavery. This includes authorities consistently taking swift and decisive action to provide a strong and non-ambiguous message; but this first requires consensus on what is the right course of action. Governments could also put greater resources into enforcement, find ways of consolidating or working across the various agencies involved in detecting and remediating modern slavery, and tighten up legislation so firms are held to account. This discussion leads to the final propositions:

P1d: Indirect intervention to address the modern slavery threat via whistleblowing is decoupled from indicators of modern slavery risks when witnesses lack clarity on how they can anonymously report their concerns and how the receiver of the information will respond. 
P2d: Clear, consolidated and anonymous communication channels will enable modern slavery whistleblowing, but for witnesses to intervene it is important that they are confident the actors receiving any information will take the threat seriously, have the resources to respond, and have a protocol in place to take swift and consistent action.

\subsection{A Model of the Bystander Effect on Modern Slavery Whistleblowing}

The above discussion on the factors affecting whistleblowing behaviour is summarised in Figure 1. The figure shows a process model of a witness receiving indicators of modern slavery in the supply chain and making an indirect intervention by whistleblowing, which forms part of a supply chain's toolkit for detecting modern slavery and improving supply chain intelligence. In the figure, identifying the problem is however decoupled from whistleblowing by four bystander factors, as described above: the low-emergency evaluation of the threat; the highly ambiguous environment; the low responsibility felt by the bystander; and, the low incentive to assist. This can form the basis of future research for improving the effectiveness of whistleblowing. Initial suggestions on some of the ways in which these factors can be addressed were also discussed above and are included in the figure. The propositions are clearly indicated on the figure (P1 \& P1a-P1d and P2 \& P2a-P2d).

It is also important to consider why organisations in particular may not always take whistleblowing reports seriously or follow up on reports in a comprehensive manner, although of course it does not have to be the focal firm that receives the report. Are there individual, behavioural factors at play? For example, are individuals already aware of the problem and have turned a blind eye, perhaps linked to having a detachment from the victims or an ignorance of the consequences for victims? Do they as buyers feel partially responsible for the problem and are in denial? Or does the lack of hard evidence mean they can brush the report away as hearsay? Furthermore, is fear a factor? For example, do individuals fear for the company's reputation or are they concerned about the legal ramifications for the firm, or for them as individuals, if modern slavery is indeed uncovered? Do they feel helpless to deal with the problem given the size and complexity of many supply chains, or fear that once they pull back the veil the whole supply chain might unravel? In addition, what role does corporate structure and culture play in the process? For example, what training has been provided to individuals on modern slavery or on handling whistleblowing reports? Is there a hierarchical structure in place for sustainability and escalating whistleblowing concerns, or does this vie with the many other competing priorities on a procurement manager's desk? Is there a strong sustainability culture in the firm, or does the economic logic and competitive pressure to reduce costs dominate? Is the company prepared to invest time and money in remediation, and how are other firms in the industry handling the threat? Finally, many of the factors that contribute to bystander behaviour, such as a shared lack of responsibility, could also contribute to how recipients of whistleblowing reports respond. 


\begin{tabular}{|c|}
\hline Low Emergency Scenario \\
(P1a) \\
- The continuous (rather than \\
discrete) threat posed by \\
modern slavery \\
- A hidden, complex problem \\
with minimal observable \\
sources of hard evidence \\
- Limited understanding of \\
links to organised crime
\end{tabular}

\begin{tabular}{|l|}
\hline$\frac{\text { High Ambiguity Environment }}{\text { (P1b) }}$ \\
- Broad, societal problem \\
known to many within a \\
community \\
- Worker's status as a victim \\
is sometimes unclear \\
- Hesitancy of onlookers \\
misunderstood as a lack of \\
concern \\
\end{tabular}

\begin{tabular}{|l|}
\hline Low Bystander Responsibility \\
(P1c) \\
- Cultural distance between \\
bystander and victim \\
- Low status of marginalised \\
victims \\
- Consumer complicity \\
- Deflection of responsibility \\
to other, more powerful \\
actors
\end{tabular}

\begin{tabular}{|l|}
\hline Low Assistance Incentive \\
- Crid) \\
direct intervention \\
challenging \\
- Direct interventions difficult \\
when there is no single, \\
discrete event \\
- Multiplicity of actors \\
undermines clear reporting \\
- Powerful actors not taking \\
the problem seriously \\
\hline
\end{tabular}

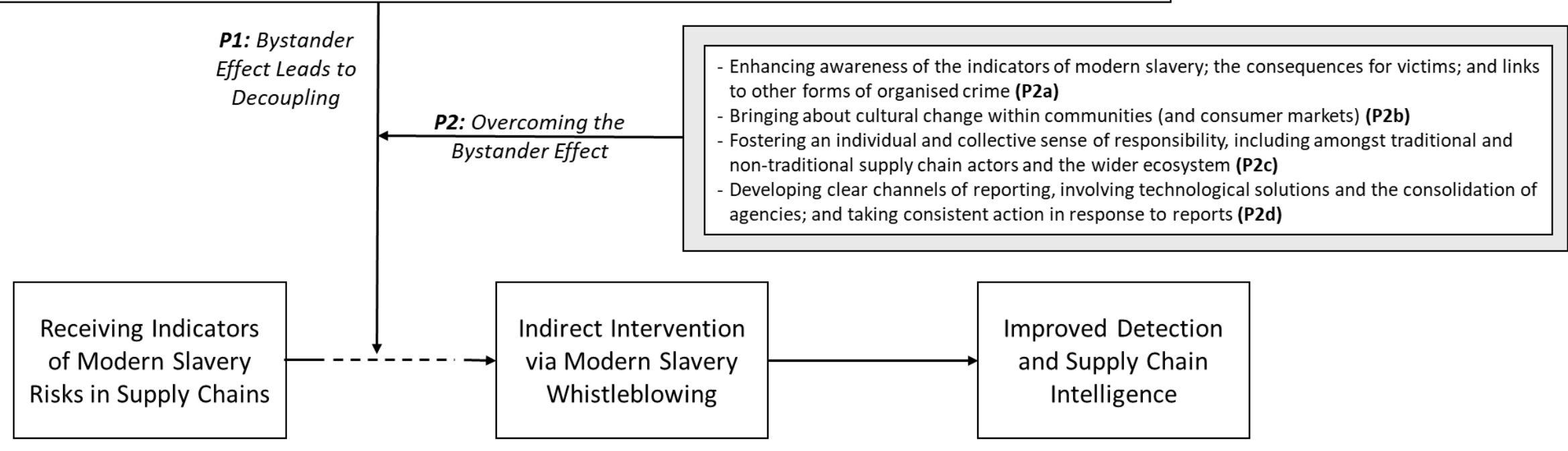

Figure 1: Factors Affecting Bystander Behaviour in the Context of Modern Slavery 


\section{Discussion and Future Research Agenda}

\subsection{Discussion of General Lessons Learned from the Focal Case}

The Leicester case reminds us that modern slavery is not a problem confined to the developing world there is no global north vs. south divide. It is happening in the UK and is widespread in many other parts of the developed world. This severely questions the right of major Western corporations to play the paternalistic, neo-colonial role in supply chains that they either willingly adopt or have thrust upon them (e.g. Drebes, 2016; Ozkazanc-Pan, 2019). Furthermore, it questions the effectiveness of reshoring or nearshoring as a suitable strategy for controlling sustainability risks, as has been suggested by some authors (e.g. Moore et al., 2018). Moreover, the presence of unethical firms like these garment factories in the UK remains a major problem that has not been addressed by efforts to increase the transparency of supply chains. Thus, the Leicester case adds further weight to criticism that government legislation, such as the UK's modern slavery act, does not go far enough in addressing the problem. Research has previously shown that many firms have made only token-gesture-like responses to the legislation and some have failed to provide statements altogether (Stevenson \& Cole, 2018; Voss et al., 2019). This calls for further action as it should not have taken the COVID-19 pandemic for these factories to be brought to justice. This of course also holds for previous scandals, including the devastating case of the Rana Plaza building collapse in Bangladesh (e.g. Huq \& Stevenson, 2020). Further, although the initial attention of the Leicester case, as reported in the media, was on the workers and garment factories, attention quickly turned to the high-profile retailers buying the garments who subsequently received major negative publicity. Thus, the case reaffirms the intimate relationship between a firm's global sourcing decisions and both its reputation and value.

The complexity of the ownership and contracting relationship between boohoo.com and one of the main factories at the centre of the scandal (The Daily Mail, 2020a) also reminds us of the challenge of mapping supply chains and the difficulty for brands to know where their products come from, especially when subcontracting takes place by upstream suppliers. This is acknowledged in boohoo.com's 2019 modern slavery statement, which stated that: "We recognise that our supply chain is complex and goes beyond the 'first tier'. The supply chain additionally includes sub-contractors, fabric and component suppliers and raw material suppliers. We are committed to improving traceability beyond the first tier of the supply chain. We continue to develop a second tier subcontractor database as part of our drive to increasing transparency within the wider supply chain". This lends support to the significant negative stock market reaction to the passing of the California Transparency in Supply Chains Act for large, complex firms with high supply chain risks, as reported by Birkey et al. (2018).

Large firms quickly distanced themselves from the Leicester scandal, severing ties with the garment factories and other actors that were implicated. The swift nature of the decisions taken by some firms may imply coordinated, collective action in response to the modern slavery threat, as advocated in Benstead et al. (2018). This however reopens the debate about what the best course of action is to take when modern slavery is uncovered. One extreme of the argument is that buyers are complicit in modern 
slavery if they do not terminate the relationship immediately and report any evidence to the authorities (New, 2015). When taking a more systems view of the problem, terminating a relationship and closing a factory may only serve to redirect vulnerable workers towards even worse conditions and even more dangerous working environments (Huq et al., 2014); hence, the other extreme, is to adopt a workercentric approach by liaising with the supplier to address the problems through remediation (Gold et al., 2015). Of course there are various points in-between these two extremes, e.g. suspending the relationship or putting the supplier on a close-watch list, with the most suitable response arguably being dependent on the severity of the violation. In the case of boohoo.com, it is stated in their 2019 modern slavery statement that: "Working in partnership with our suppliers to help them address issues within their operations is important to us; we recognise that some issues cannot be solved overnight, but with guidance, our suppliers can implement sustainable change."

Meanwhile, researchers have advocated the importance of brands looking inwardly at their own practices and how they contribute to the threat of modern slavery (New, 2015; Stevenson \& Cole, 2018), and this is certainly reaffirmed by the Leicester case. By charging low prices to consumers of fast fashion, where product lines are continuously changing in response to the latest catwalk trends, brands put severe pressure on factories to produce at low cost and in double-quick time or to subcontract to others that are able to do so. In this case, there was a particularly sharp shift in customer demand due to the nation-wide lockdown, which led to growing demand for loungewear clothing, a slump in demand for formal wear, and a reduction in the number of firms able to satisfy demand (limited to those with an online presence). High-profile firms like those linked to this scandal are likely to have been very keen to capitalise on this market opportunity leading to downward pressure on their supply chain partners. These are the sorts of COVID-19-induced conditions that Trautrims et al. (2020) recently warned could lead to greater modern slavery risks in supply chains.

In addition to the above general lessons, there are a number of implications for future research that emerge from the paper's focus on whistleblowing and the bystander effect. Thus, seven future research directions are outlined in the subsection below before the paper concludes in Section 6.

\subsection{A Future Research Agenda}

Various future research directions emerge from the focus of this paper. With regards to encouraging greater whistleblowing, it is important that reporting is as straightforward as possible when an actor detects a modern slavery threat. Therefore, the first future research suggestion is to conduct studies focused on developing a single point of reporting for modern slavery issues, so witnesses know more clearly who they should report to and how they can report. It is often the case that there are multiple avenues for reporting, which may provide the witness with options, but it also creates confusion and both a lack of transparency and responsibility. In this respect, it is likely that multi-stakeholder studies will be important, including various forms of horizontal collaboration and the presence of traditional and non-traditional supply chain actors. Technology is key to improving whistleblowing, with various 
anonymous hotlines, applications and websites available; therefore, the second future research suggestion is to undertake studies that examine how technology can be enhanced to encourage whistleblowing. This includes overcoming any barriers to the acceptance and widespread adoption of whistleblowing applications. This can best be undertaken using a multidisciplinary approach, including social sciences, technological and communications experts. Enabling reporting is a step forward, but it is only useful if reports are taken seriously and acted upon consistently. This is a complex issue that may involve seeking to simultaneously protect the victims and prosecute criminals that have taken advantage of them. The third future research suggestion is to conduct studies focused specifically on the recipients of whistleblowing reports. This includes their protocols for handling disclosures, how they might triangulate reports with other forms of intelligence on the supply chain and, in the case of focal firms and their remediation practices, determining how firms and other stakeholders should respond if and when whistleblowing reports have been verified.

Further, there are opportunities to build more directly on the contribution of this paper and to extend its scope. The fourth future research suggestion is therefore to conduct confirmatory work that operationalises the propositions put forward in the form of more testable hypotheses. In addition, the fifth future research suggestion is to undertake supplementary work that focuses on whistleblowing from within the supply chain, including by victims themselves as participant bystanders. The Leicester case referred to the intimidation of factory workers while the bystander effect literature referred to the value of reporting lines going outside a victim's organisation (and supply chain). Incentivising greater whistleblowing by workers and other supply chain actors is therefore likely to be difficult and may rely on creating a safer space for the worker voice to be heard, irrespective of a worker's legal immigration status in the country. At present, the worker/victim voice is not being sufficiently heard in operations and supply chain management studies on modern slavery, although enabling this is acknowledged to be very challenging. It will also be important to consider the incentives/disincentives of actors within the supply chain to report their observations as these may be different to those of the general public. This could similarly be approached using the lens of the bystander effect. The present paper has provided a first application of the bystander lens to modern slavery, and this could be deepened in future research.

This paper has emphasised the importance of bundles of practices - tackling the complexity of the modern slavery threat with a multiplicity of responses - and of connecting with the communities in which a firm or supply chain is embedded, both to 'give back' and benefit from local knowledge or tacit understanding. The sixth future research suggestion is to undertake work on the toolkit of practices available for tackling modern slavery and how they interact. While this paper has emphasised how whistleblowing can complement auditing, it would be beneficial to examine how other practices can be combined effectively to respond to the threat. The seventh and final future research suggestion is to conduct highly engaged empirical studies that extend the focus of supply chain research by giving greater consideration to the communities in which supply chains are embedded, e.g. considering the consequences of operations and supply chain decisions on local communities, connecting work on 
modern slavery in supply chains with the victim-worker, and by exploring how firms and communities can work together to tackle the threat.

\section{Conclusions}

Modern slavery is one of the most important contemporary challenges to supply chains, and it is a problem that is set to become even more acute in the aftermath of COVID-19. To date, the specific challenge of modern slavery has received only limited attention in the operations and supply chain management literature, where the focus has largely been on traditional supply chain actors and on considering individual practices for detecting and/or remediating modern slavery. It has been argued in this paper that modern slavery can best be tackled:

(i) Collectively, not only incorporating traditional and non-traditional supply chain actors but also governments and members of the wider community; and,

(ii) By combining practices to make better use of limited resources, particularly in large-scale, globally dispersed supply chains, thereby helping the focal firm to overcome information asymmetry and its lack of a direct contractual relationship with sub-tiers.

The study begins to connect operations and supply chains to the local community in which they are embedded through a focus on the bystander effect and its impact on the general public in the context of modern slavery. If causes of the bystander effect can be overcome then supply chains can mobilise the general public to whistle-blow, thereby enabling them to exploit a potentially important source of intelligence about the modern slavery threat. A broad definition of whistleblowing has been adopted in this paper to include any act of information disclosure undertaken by anyone that seeks to draw attention to wrongdoing within an organisation.

Building on the above, whistleblowing is currently an under-utilised practice for gathering greater intelligence on the supply chain but one that could be used to direct the use of a firm's scarce auditing resources for detection towards the most high-risk nodes in the supply chain. This is particularly important given the difficulties of scaling up other practices for maintaining the visibility of modern, global supply chains (Benstead et al., 2020), especially in the post-COVID-19 world (Trautrims et al., 2020). Thus, understanding the bystander effect and addressing its causes supports firms and supply chains in operationalising the practice of whistleblowing and ultimately the detection and remediation of modern slavery. This will allow firms to recruit many eyes and ears around the world to continuously watch and report on their global supply chains. But this relies, for example, on elevating the emergency status of modern slavery, avoiding ambiguity by being clear and consistent on the threat posed by modern slavery, creating a shared sense of responsibility for tackling the problem, having clear channels of communication for reporting violations, and taking swift and consistent action when instances of modern slavery are detected. The focus of this paper has been on whistleblowing by members of the local community while future research could extend the study to whistleblowing by victims and other 
internal members of an organisation or supply chain - as indicated in the future research agenda outlined above.

\section{References}

Andrade, J. A. (2015). "Reconceptualising whistleblowing in a complex world”. Journal of Business Ethics, 128 (2), 321-335.

Barrientos, S., and Smith, S. (2007). "Do Workers Benefit from Ethical Trade? Assessing Codes of Labour Practice in Global Production Systems.” Third World Quarterly 28(4), 713-729.

Barrientos, S. (2008). "Contract labour: The 'Achilles heel' of corporate codes in commercial value chains". Development and Change, 39(6), 977-990.

Barrientos, S. W. (2013). “'Labour chains': analysing the role of labour contractors in global production networks". The Journal of Development Studies, 49(8), 1058-1071.

BBC. (2020a). “Coronavirus: 'Big problem' at Leicester factories, say workers”. https://www.bbc.co.uk/news/uk-england-leicestershire-53311548 (last accessed on $8^{\text {th }}$ August 2020).

BBC. (2020b). "Boohoo dropped by Next, Asos and Zalando over exploitation claims". https://www.bbc.co.uk/news/business-53327628 (last accessed on $8^{\text {th }}$ August 2020).

BBC. (2020c). "Leicester lockdown factories 'almost doubled staff' during Covid-19”. https://www.bbc.co.uk/news/uk-england-leicestershire-53363102 (last accessed on $8^{\text {th }}$ August 2020).

BBC. (2020d). "Boohoo appoints former judge Sir Brian Leveson to probe company's ethics”. https://www.bbc.co.uk/news/business-55083915 (last accessed on 16 ${ }^{\text {th }}$ December 2020).

Benstead, A. V., Hendry, L. C., and Stevenson, M. (2018). "Horizontal collaboration in response to modern slavery legislation”. International Journal of Operations \& Production Management, 38(12), 2286-2312.

Benstead, A. V., Hendry, L. C., and Stevenson, M. (2020). "Detecting and remediating modern slavery in supply chains: a targeted audit approach". Production Planning \& Control, 1-22.

Birkey, R. N., Guidry, R. P., Islam, M. A., and Patten, D. M. (2018). "Mandated social disclosure: An analysis of the response to the California Transparency in Supply Chains Act of 2010”. Journal of Business Ethics, 152(3), 827-841.

Carrington, M., Chatzidakis, A., and Shaw, D. (2020). "Consuming Worker Exploitation? Accounts and Justifications for Consumer (In) action to Modern Slavery". Work, Employment and Society, 0950017020926372.

Chaudhry, P. E., and Stumpf, S. A. (2011). "Consumer complicity with counterfeit products". Journal of Consumer Marketing, 28(2), 139-151.

Clark, R. D., and Word, L. E. (1972). “Why don't bystanders help? Because of ambiguity?” Journal of Personality and Social Psychology, 24(3), 392-400.

Cooke, B. (2003). “The denial of slavery in management studies”. Journal of Management Studies, 40(8), 18951918.

Cousins, P., Dutordoir, M., Lawson, B., and Neto, J. Q. F. (2020). "Shareholder wealth effects of modern slavery regulation". Management Science.

Crane, A. (2013). "Modern slavery as a management practice: Exploring the conditions and capabilities for human exploitation". Academy of Management Review, 38(1), 49-69. 
Darley, J. M. and Latané, B. (1968). "Bystander intervention in emergencies: Diffusion of responsibility". Journal of Personality and Social Psychology. 8 (4, Pt.1): 377-383.

Darley, J. M., and Latane, B. (1970). “The unresponsive bystander: why doesn't he help?” New York, NY: Appleton Century Crofts.

Dozier, J. B., and Miceli, M. P. (1985). "Potential predictors of whistle-blowing: A prosocial behavior perspective". Academy of Management Review, 10(4), 823-836.

Drebes, M. J. (2016). “Including the 'Other': Power and Postcolonialism as Underrepresented Perspectives in the Discourse on Corporate Social Responsibility." Critical Sociology 42(1), 105-121.

Financial Times. (2020). "Leicester hits out at ministers over labour abuse claims". https://www.ft.com/content/0d18d5c5-496f-4869-9ac2-7ff7663b3629 (last accessed on $8^{\text {th }}$ August 2020).

Fischer, P. Krueger, J.I., Greitemeyer, T., Vogrincic, C., Kastenmüller, A., Frey, D., Heene, M., Wicher, M., and Kainbacher, M. (2011). "The bystander-effect: a meta-analytic review on bystander intervention in dangerous and non-dangerous emergencies." Psychological Bulletin 137(4), 517-537.

Flynn, A. (2019). "Determinants of corporate compliance with modern slavery reporting". Supply Chain Management: An International Journal, 25(1), 1-16.

Flynn, A., and Walker, H. (2020). "Corporate responses to modern slavery risks: an institutional theory perspective". European Business Review.

Gao, J., Greenberg, R., and Wong-On-Wing, B. (2015). "Whistleblowing intentions of lower-level employees: The effect of reporting channel, bystanders, and wrongdoer power status". Journal of Business Ethics, 126(1), $85-99$.

Gold, S., Trautrims, A., and Trodd, Z. (2015). "Modern slavery challenges to supply chain management". Supply Chain Management: An International Journal, 20(5), 485-494.

Huq, F. A., Stevenson, M., and Zorzini, M. (2014). "Social sustainability in developing country suppliers". International Journal of Operations \& Production Management, 34(5), 610-638.

Huq, F. A., and Stevenson, M. (2020). "Implementing socially sustainable practices in challenging institutional contexts: building theory from seven developing country supplier cases". Journal of Business Ethics, 161(2), 415-442.

Jubb, P. B. (1999). "Whistleblowing: A restrictive definition and interpretation". Journal of Business Ethics, 21 (1), 77-94.

Kara, S. (2017). “Modern slavery: A global perspective”. Columbia University Press.

Lancs Live. (2019). “'Risk to life just as real' as Morecambe Bay cockling tragedy remembered 15 years on”. https://www.lancs.live/news/lancashire-news/risk-life-just-real-morecambe-15782984 (last accessed on $8^{\text {th }}$ August 2020).

Latané, B; Darley, J.M. (1968). "Group inhibition of bystander intervention in emergencies". Journal of Personality and Social Psychology. 10(3), 308-324.

Latané, B., \& Rodin, J. (1969). "A lady in distress: Inhibiting effects of friends and strangers on bystander intervention”. Journal of Experimental Social Psychology, 5(2), 189-202.

Levine, M. (2012). “Helping in emergencies: Revisiting Latané and Darley's bystander studies”. In J. R. Smith and S. A. Haslam (Eds.), "Psychology: Revisiting the classic studies. Social psychology: Revisiting the classic studies” (p. 192-208). Sage Publications Ltd. 
Mason, D., and Allen, B. P. (1976). “The bystander effect as a function of ambiguity and emergency character”. The Journal of Social Psychology, 100(1), 145-146.

Mesmer-Magnus, J. R., and Viswesvaran, C. (2005). "Whistleblowing in organizations: An examination of correlates of whistleblowing intentions, actions, and retaliation”. Journal of Business Ethics, 62(3), $277-297$.

Moore, M. E., Rothenberg, L., and Moser, H. (2018). “Contingency factors and reshoring drivers in the textile and apparel industry”. Journal of Manufacturing Technology Management, 29(6), 1025-1041.

New, S. J. (2015). "Modern slavery and the supply chain: the limits of corporate social responsibility?". Supply Chain Management: An International Journal, 20(6), 697-707.

Ozkazanc-Pan, B. (2019). "CSR as Gendered Neocoloniality in the Global South.” Journal of Business Ethics 160 (4): 851-864.

Schwartz, S. H., and Gottlieb, A. (1980). "Bystander anonymity and reactions to emergencies". Journal of Personality and Social Psychology, 39(3), 418.

Solomon, L. Z., Solomon, H., and Maiorca, J. (1982). “The effects of bystander's anonymity, situational ambiguity, and victim's status on helping”. The Journal of Social Psychology, 117(2), 285-294.

Stevenson, M., and Cole, R. (2018). "Modern slavery in supply chains: a secondary data analysis of detection, remediation and disclosure". Supply Chain Management: An International Journal, 12(3), 81-99.

The Daily Mail. (2020a). “Boohoo's links to Leicester 'slave' factory revealed: Business partner of clothing brand's co-founder owns warehouse accused of paying employees $£ 3.50$ per hour”.

https://www.dailymail.co.uk/news/article-8511719/Boohoo-founders-links-Leicester-slave-factoryrevealed.html (last accessed on $8^{\text {th }}$ August 2020).

The Daily Mail. (2020b). “'Fear of being called racist' stopped police from tackling Leicester's 'slave' sweatshops, Priti Patel believes". https://www.dailymail.co.uk/news/article-8513825/Fear-called-racist-stopped-policetackling-sweatshops-Priti-Patel-believes.html (last accessed on $8^{\text {th }}$ August 2020).

The Guardian. (2004). "Tides kill 19 cockle pickers". https://www.theguardian.com/world/2004/feb/06/china.uk (last accessed on $8^{\text {th }}$ August 2020).

The Guardian. (2020a). "Leicester's coronavirus lockdown is no surprise to its garment factory workers". https://www.theguardian.com/commentisfree/2020/jul/03/leicester-coronavirus-lockdown-is-no-surprise-toits-garment-factory-workers (last accessed on $8^{\text {th }}$ August 2020).

The Guardian. (2020b). "The Leicester garment factories exposed by Covid-19”. https://www.theguardian.com/news/audio/2020/jul/09/the-leicester-garment-factories-exposed-by-covid-19 (last accessed on $8^{\text {th }}$ August 2020).

The Guardian. (2020c). "More than £1bn wiped off Boohoo value as it investigates Leicester factory". https://www.theguardian.com/business/2020/jul/06/boohoo-leicester-factory-conditions-covid-19 (last accessed on 8th August 2020).

The Guardian. (2020d). "'Slob style' is the Covid-19 fashion statement. But will it survive after lockdown?". https://www.theguardian.com/commentisfree/2020/jul/01/slob-style-covid-19-fashion-statement-lockdowndominic-cummings (last accessed on $8^{\text {th }}$ August 2020).

The Guardian. (2020e). "Priti Patel is wrong, modern slavery in Leicester is built on her government's failures". https://www.theguardian.com/commentisfree/2020/jul/14/priti-patel-modern-slavery-leicester-culturalsensitivities (last accessed on $8^{\text {th }}$ August 2020). 
The Independent. (2020a). "Boohoo 'facing modern slavery investigation' after report finds Leicester workers paid as little as $£ 3.50$ an hour”. https://www.independent.co.uk/news/uk/home-news/boohoo-leicesterfactories-modern-slavery-boohoo-leicester-factories-modern-slavery-investigation-a9602086.html (last accessed on $8^{\text {th }}$ August 2020).

The Independent. (2020b). "Boohoo appoints retired judge Sir Brian Leveson to move on from supply chain scandal", https://www.independent.co.uk/news/uk/boho-sir-brian-leveson-supply-chain-b1762164.html (last accessed on $16^{\text {th }}$ December 2020).

The Telegraph. (2020). "Fast fashion's sins have been hiding in plain sight". https://www.telegraph.co.uk/business/2020/07/14/fast-fashions-sins-have-hiding-plain-sight/ (last accessed on $8^{\text {th }}$ August 2020).

The Times. (2020a). "Boohoo: fashion giant faces slavery investigation". https://www.thetimes.co.uk/article/boohoo-fashion-giant-faces-slavery-investigation-57s3hxcth (last accessed on $8^{\text {th }}$ August 2020).

The Times. (2020b). "The secret's finally out — now the sweatshops must close". https://www.thetimes.co.uk/article/the-secrets-finally-out-now-the-sweatshops-must-close-vlbsth6jd (last accessed on $8^{\text {th }}$ August 2020).

The Washington Post. (2020). "5 ways the pandemic is changing fashion and beauty trends". https://www.washingtonpost.com/business/2020/06/15/fashion-beauty-trends-coronavirus/ (last accessed on $8^{\text {th }}$ August 2020).

Trautrims, A., Schleper, M. C., Cakir, M. S., and Gold, S. (2020). "Survival at the expense of the weakest? Managing modern slavery risks in supply chains during COVID-19”. Journal of Risk Research, 1-6.

Voss, H., Davis, M., Sumner, M., Waite, L., Ras, I. A., Singhal, D. I. V. Y. A., and Jog, D. (2019). "International supply chains: compliance and engagement with the Modern Slavery Act”. Journal of the British Academy, $7(1), 61-76$.

You, L., and Lee, Y. H. (2019). "The bystander effect in cyberbullying on social network sites: Anonymity, group size, and intervention intentions". Telematics and Informatics, 45, 101284. 